At the institutional level, use rankings for strategic planning and quality improvement purposes. Tertiary education institutions that look at detailed ranking data for benchmarking purposes can use specific indicators to understand the determinants of their performance and then work toward improving the quality of teaching and research.

At the government level, use rankings to stimulate a culture of quality. In countries that do not yet have a well-established quality assurance system, rankings can be used as a proxy for quality. Similarly, at the international level, in the absence of a single global quality assurance agency, ranking systems take on some characteristics of a quality regulator for international students.

Use rankings as one of the instruments available to inform stakeholders. Rather than being considered as the ultimate measure of quality and/or relevance, rankings should be complemented by information on accreditation and labor market outcome data collected through surveys of employers and tracer surveys. The results of league tables can also serve to generate a national debate about long-term strategic priorities and policies for tertiary education.

\section{The Role of Higher Education Institutions in Innovation and Economic Development}

\section{SaCHI Hatakenaka}

Sachi Hatakenaka is an independent consultant and researcher on higher education policy and management and is currently affiliated to the Industrial Performance Center at the Massachusetts Institute of Technology for her research. E-mail: sachi@alum.mit.edu.

$\mathbf{C}$ everal decades of debate and experimentation are leading to $\checkmark$ an understanding worldwide that many (but not all) universities can play diverse but important roles in innovation and economic development.

\section{Diverse Roles}

Scientific discoveries leading to industrial innovations, particularly through academic spin-offs, provide a classic image of universities contributing to economic development (e.g., Silicon Valley and Route I28). Many research institutions struggle to replicate this; universities may not have the culture or capability to do so. Yet some universities surround themselves with a local industrial community that can absorb and make use of scientific discoveries to accrue economic benefits. For spin-offs to be successful, the university must reside within a supportive ecosystem with technology-aware financial investors, managerial capacity, and other professional resources.

A second way universities can support economic development is providing updated technical knowledge and skills in the workforce. Though less "sexy" or highlighted, universities can play this important role at all levels. Not only do a small number of R\&D scientists need their knowledge to be updated but also a large number of midlevel technical professionals and even larger numbers of technical workers. One global optoelectronics company in Japan had a well-developed international network with cutting-edge scientists for its R\&D activities. The company also appreciated its less visible ties with

Scientific discoveries leading to industrial innovations, particularly through academic spin-offs, provide a classic image of universities contributing to economic development

academics at local universities because it was these relationships that impacted a large number of company employees and helped them keep abreast of scientific progress.

There is a complementary role in which academics undertake joint research, consultancy, or contract work with industry to help address various technological problems. This interaction with industry allows academics to learn about industrial needs, but the relationships inform them equally about what is relevant.

Universities can play a less direct yet important economic role by setting forth the social, cultural, and intellectual tone of a local area. Cultural events surrounding universities can make a place more attractive to educated professionals and their employers. The University of Pennsylvania goes further and makes an institutional commitment to community development in its neighborhood.

Other roles relevant to economic development include contributing to government and industrial decision making by participating in key committees and advisory boards and expanding local economic activities.

\section{Relevance as a University Mission}

In many countries, higher education institutions are or aspire to be focused on academic research with little practical orientation. There is also a strong tendency for academic and research drift. Institutions with a practical orientation often become more academic, and teaching-focused institutions become more research oriented. One reason for these changes has been the dominant interpretation of "scientific autonomy," which was often interpreted to encourage isolation from external stakeholders.

Today it is seen as possible for scientists to undertake fundamental research while being motivated by practical relevance-rather like Pasteur, the French biologist known for his 
scientific research with significant societal impact. Indeed, for some research universities, relevance is an integral part of their mission, even as they aspire to be at the cutting edge of research-the Massachusetts Institute of Technology (MIT), for example. While not all academics at research universities engage in practically relevant research, MIT encourages research focused on areas with a significant expected impact. MIT has mechanisms for supporting interdisciplinary research with many professional researchers (not just postdocs or junior academics). This approach provides a contrast to senior academics in other countries-for instance in the United Kingdom-whose performance is more tightly evaluated according to their scientific publications.

Forward looking, teaching-focused institutions with a mission to provide relevant skills can also play a key role. They help build "absorptive capacity" even if scientific discoveries are not made locally. By quickly building human resources with key knowledge and skill, universities can help develop responsiveness in the labor market. Typical academics in such institutions may not be known for cutting-edge science or major publications, but understand the direction of scientific progress and can update their education programs to meet emerging industrial needs.

\section{InTRODUCING ReLEVANCE}

It is not easy to introduce a culture of relevance. One key opportunity arises in founding new institutions, particularly as a group. Ireland's drive to found multiple new institutions with a practical orientation in the I970s pushed other established ivory tower research institutions to pay more attention to practical relevance.

The "founding ethos" can have a lasting influence on an institution, as exemplified by US land grant institutions. MIT

\section{Universities can play a less direct yet important economic role by setting forth the social, cultural, and intellectual tone of a local area.}

was also such an example, even as it developed from a teaching-dominated technical institution to a world-class research university-from its birth in the late igth century to the early 2oth century-its founding ethos of practical relevance had a lasting impact.

Another opportunity occurs when there is a sense of national (or regional) crisis. Many US universities became more serious about their contribution to the economy during the I980s when the country was undergoing a competitiveness crisis. In Japan, in the I990s, after a decade of economic stagnation, politicians, industrialists, and the media all urged universities to become active agents for economic restructuring. The societal needs were so compelling that many academics felt a moral pressure to oblige and are now responding to the chal- lenges.

A lack of funds can also help push universities to forge ties with industry as they seek alternative funding. Katholik University of Leuven (KUL) in the late I96os experienced a turning point as it had little funds; it had to become entrepreneurial and work with industry. MIT in its early days had insufficient funds to pay full salaries to professors, and so they were encouraged to undertake consulting. In the ig8os and I990s the perception that federal funding was less available led many US institutions to turn to industry. However, money as a driver often leads to only superficial changes. For instance, in many countries, academics moonlight extensively and have broad ties with industry, and yet their institutions may produce little relevant research or updated curricula. The difference between these and practically relevant institutions lies in the level of organizational commitment; KUL and MIT not only legitimated industrial ties but expanded them and used the links as an organizational mechanism to remain connected to the external world.

Finally, government can play a critical role. In the United States, an ethos of "service" was established in land grant institutions largely through government support for universities in agricultural and industrial extension services. Subsequently, government made large investments in basic scientific research at universities, but usually in practically relevant fields. Basic research funding from application-motivated agencies (defense or health) significantly affected the research agenda. Over time, the US industry appears to have become better users of science. Increasing numbers of scientists are joining industry, and government grants given to industry allow them to conduct research and interact with universities.

More recently, in Belgium, government investment has helped to establish internationally competitive applied research institutes in key fields such as microelectronics and biotechnology, bringing together universities with industrial partners. In the United Kingdom, government funding for "third mission activities" has helped academics as well as administrators work closely with industry and other sectors, providing valuable learning and networking opportunities.

A good starting point for building relevance is a dialogue between universities, industry, and government. For that to be effective, society needs to drop its scepticism and believe that universities can contribute to its development, and equally academics need to recognize that they can strive for relevance without compromising their scientific integrity.

Internet Resources
Visit our Web site for downloadable back issues of
International Higher Education and other publica-
tions and resources at http://www.bc.edu/cihe/.

